\title{
Experimental Support of the Hedonistic Model of Desire
}

\author{
Alexander Ovsich \\ Information Technology, Boston College \\ St Clement's Hall 463, 140 Commonwealth Avenue \\ Chestnut Hill, MA 02467, USA \\ Tel: 1-617-552-4907Ｅ-mail: ovsich@bc.edu \\ Michel Cabanac \\ Faculty of Medicine, Laval University \\ 1855 Commerciale St-Jean-Xstome, QC, G6Z 2L2, Canada \\ Tel: 1-418-839-5648Ｅ-mail: michel.cabanac@fmed.ulaval.ca
}

Received: November 6, 2011

doi:10.5539/ijps.v4n1p66
Accepted: February 10, $2012 \quad$ Published: March 1, 2012

URL: http://dx.doi.org/10.5539/ijps.v4n1p66

\begin{abstract}
This article analyzes experiments conducted by one of the authors of the article from the point of view of the hedonistic model of desire proposed by another author. We show that these independently conducted experiments and a number of the classical definitions of desire support the proposed model of desire. The model claims that terms "desire", "want", and their cognates describe changes of the Pleasantness of the State of a Subject (PSS) associated with the desire objects, and that the magnitude of these changes is called a "strength of desire". If the change $(\Delta)$ of the PSS for a subject $S$ associated with $\mathrm{X}$ is positive/non-positive then $\mathrm{X}$ is called desirable/undesirable correspondingly. DESIRE $\mathrm{S}, \mathrm{X}=\Delta\left(\mathrm{PSS}_{\mathrm{S}, \mathrm{X}}\right)$; $\mathrm{STRENGTH}$ of DESIRE $_{\mathrm{S}, \mathrm{X}}=\left|\left(\Delta \mathrm{PSS}_{\mathrm{S}, \mathrm{X}}\right)\right|$. Main advantages of this model of desire: it is mathematically clear, supported by experiments, intuitive.
\end{abstract}

Keywords: Desire, Want, Pleasure, Pleasantness, Hedonism, Hedonic, Motivation

\section{Existing Dearth of Clarity and Consensus about the Meaning and Definition of Desire}

There are many 'ways' (Note 1) and "faces" (Note 2) of desire, but there is one fundamental question about the meaning and definition of desire that is the focus of this article. There is neither much literature nor consensus about the notion of desire. In the 1995 book "Desire. Its role in Practical Reason and the Explanation of Action" Schueler (1995,p. 6) "... focused on contemporary philosophers..." noting that "... the views I am criticizing suffer from a deep ambiguity in terms such as 'desire', 'want' and their cognates". Almost a decade later Frankfurt (2004) called the notion of desire "rampantly ubiquitous" and wrote:

"Moreover, its various meanings are rarely distinguished; nor is there much effort to clarify how they are related. These matters are generally left carelessly undefined in the blunt usages of common sense and ordinary speech" (p. 10).

The level of ambiguity in understanding desire is such that the validity of the notion of desire itself is sometimes questioned or even denied outright. For example, DeLancey (2002) wrote:

"Since my concern in this book is with basic emotions and other motivational states, I will on several occasions discuss the inappropriateness of the philosopher's notion of desire; it is hard to overestimate the harm that this notion has done to moral psychology, action theory, and other aspects of philosophy of mind. ... (for example, there are many kinds of motivational states, but no generic one corresponding to the philosophical notion of desire)..."( p. ix).

However, as Marks (1986) carefully noted:

"...it may well be the case, as I believe, that there remains a single, significant, psychological phenomenon appropriately named "desire." If so, then it is this - desire proper - which, ultimately, constitutes the subject 
matter of the theory of desire" (p. 10).

His belief is shared by the authors of this paper. This article analyzes experiments independently conducted by Cabanac in order to see whether they support the model of desire proposed by Ovsich (1998).

\section{Hedonistic Approach to Desire}

Schroeder (2004, pp. 27-31) identified two main types of the desire theories - motivational and hedonistic; he considered hedonistic theory to be superior to the motivational (Note 3). Indeed, hedonistic approach to desire has a very long and impressive history. Aristotle directly defined desire through pleasure: "Everything, too, is pleasant for which we have the desire within us, since desire is the craving for pleasure" (2004, Rhetoric, I, 11, 1370b) and the same can be said about Spinoza (1674/1955, Proposition XXXVII). As formulated by Mill (1861, p. 49), “...desiring a thing and finding it pleasant, aversion to it and thinking of it as painful, are phenomena entirely inseparable or, rather, two parts of the same phenomenon." Schroeder (2004, p.27), referring to Mill's opinion, wrote "Mill is not the only distinguished historical figure to have considered such a view." Schroeder further elaborated: "Hobbes, Hume, and Kant apparently had similar thoughts, though interpretation of these thinkers is difficult" (2004, p. 185).

In line with his clearly hedonistic definition of desire as "the craving for pleasure" quoted above, Aristotle (Rhetoric 2.2, 1378a31-3) not only defines anger as a desire for revenge (Konstan, 2006, p. 41; Kenny, 1963, p. 193) or retaliation (Tailor 1986, p. 231), but also provides rather detailed descriptions of what it means at the hedonic level:

"Revenge, too, is pleasant; it is pleasant to get anything that it is painful to fail to get, and angry people suffer extreme pain when they fail to get their revenge; but they enjoy the prospect of getting it" (Rhetoric 1.11, 1371a; also see $2.2,1378 \mathrm{~b})$.

It is important here to note that desire for revenge (anger) involves a positive hedonic change, transition from the hedonically negative to the hedonically positive state experienced even while imagining 'the prospect of getting it' (Note 4).

Aristotle's hedonistic approach to desire was echoed by Locke who defined desire as follows: "The uneasiness a man finds in himself upon the absence of anything whose present enjoyment carries the idea of delight with it, is that we call desire" (1690/1824, Book II, Chapter 20, Section 6). Desire for Locke is also about the hedonic gap between the more negative hedonic level ("uneasiness") of the state of the desiring subject without an object of desire and the more positive hedonic level ("enjoyment") with it. As for Aristotle, Locke's interpretation of desire is also about the positive hedonic change associated with the desired phenomenon.

The vital fact of the matter here is that such a hedonic gap, a positive hedonic change associated with the object of desire is a regular property of the subjective experience of desire. This is true for the "low" physiological desires as well as for the "high" psychological desires. This sameness allows one to express desire for an action, power or sex metaphorically as being "action or power hungry," "hungry for the loved one."

\section{Proposed Definition and Formula of Desire and Its Strength}

Attention of a subject moves from one phenomenon to another. The two consecutive phenomena following one another in the center of the subject's attention will need be addressed as "previous"/ "next", "old"/ "new", number (n-1) and (n), a "beginning"/ "end". Generally speaking, varying degrees or levels of Pleasantness of the State of a Subject (PSS, Note 5) correspond to perception or imagination of different phenomena. Therefore, movements of the center of attention from one phenomenon to another alter PSS, adjusting it up or down from the PSS of a former level to the PSS of the present moment. A "new" phenomenon that makes the center of attention for a subject can change the subject's PSS in three possible ways:

1) In a positive direction, maximizing PSS;

2) In a negative direction, minimizing PSS;

3) Being neutral, makes little or no change in PSS.

In other words, when a new phenomenon (number $n$ ) gets in the in the center of the subject's attention of a subject it "causes" or more accurately, is associated with a change of PSS from the PSS level correspondent to the previous central phenomenon (n-1) that is $\mathrm{PSS}_{\mathrm{n}-1}$ to the $\mathrm{PSS}_{\mathrm{n}}$. The simple mathematics of this change can be expressed as follows:

$$
\Delta \mathrm{PSS}_{\mathrm{n}}=\mathrm{PSS}_{\mathrm{n}}-\mathrm{PSS}_{\mathrm{n}-1}=\mathrm{PSS}_{\mathrm{end}}-\mathrm{PSS}_{\mathrm{bgn}}
$$


The model of desire presented in Ovsich (1998a, 1998b) and discussed here is based upon the Hedonistic principle declaring that humans are driven to maximize pleasantness of their internal state (Pleasantness of the State of a Subject or PSS here). The direct inference from the Hedonistic principle is, that one of the most important for such a subject characteristics of any phenomenon X should be X's ability to maximizes/minimizes PSS. For a human subject, it also means that words and expressions describing PSS changes ought to be notable and widely used. Ovsich theorized that terms such as "desire", "want", and their cognates describe PSS changes occurring when a perceived or imagined phenomenon (desire object) gets in the center of attention of a subject, and that the magnitude of the PSS change is called a "strength of desire". Ovsich proposed that expressions calling a phenomenon X "desirable/undesirable", "wanted/unwanted", etc., for the subject S characterize X as a factor of maximization/non-maximization (correspondingly) of PSS for the subject; that these expressions associate $\mathrm{X}$ with the positive/non-positive (negative or zero) $\triangle \mathrm{PSS}_{\mathrm{S}, \mathrm{X}}$.

PSS can change in the three possible ways: in a positive direction, in a negative direction, or not change it at all. In other words, there are three basic cases: $\Delta \mathrm{PSS}_{\mathrm{S}, \mathrm{X}}>0 ; \Delta \mathrm{PSS}_{\mathrm{S}, \mathrm{X}}=0 ; \Delta \mathrm{PSS}_{\mathrm{S}, \mathrm{X}}<0$. These three possible cases of the PSS change and their predicted desirabilities can be presented in the following table:

\section{Insert Table 1 Here}

The common feature in cases/rows two and three is a non-positive (zero or negative) change of PSS ( $\triangle \mathrm{PSS}_{\mathrm{S}, \mathrm{x}}<=$ 0 ) or an absence of the positive change of PSS. It indicates, that a subject reports a presence or absence of desire for a phenomenon depending upon the presence or absence of the positive change of PSS associated with that phenomenon, i.e., that what is usually called "desire" of X is a positive change of PSS associated with X; an object of desire is a factor of PSS maximization. From the hedonistic viewpoint it is quite clear why a positive rather than a negative or zero change of PSS is used as the bases for terms "desire" and "want" describing PSS alteration. According to the Hedonistic Principle, a subject is looking for maximization of PSS that is represented by a positive PSS change, $\Delta \mathrm{PSS}_{\mathrm{S}, \mathrm{X}}>0$. The use of the negative prefixes to describe something as "Undesirable", "Unwanted", points to the absence of or opposite to the positive PSS change that subjects are seeking.

If we interpret desire as an algebraic variable that can be positive or negative (where the 'desirable X' means that $\mathrm{X}$ is an object of the positive desire and 'Undesirable $\mathrm{X}$ ' means that $\mathrm{X}$ is an object of the negative desire), then we can define the desire of $\mathrm{X}$ in general as a term describing a change of PSS $\left(\triangle \mathrm{PSS}_{\mathrm{S}, \mathrm{X}}\right)$ associated with $\mathrm{X}$. Here is the definition of a desire: a subject's (S) desire for $X$ is a word to describe a change of the Pleasantness of the State of this Subject $\left(\triangle \mathrm{PSS}_{\mathrm{S}, \mathrm{X}}\right)$ associated with (or "caused" by) the perception or imagination of X. Desirability of $X$ for $S$ is an ability of $X$ to maximize PSS that is characterized by $\triangle P S S_{S, x}$.

Below is the formula of desire that incorporates all three types of the $\triangle \mathrm{PSS}$, and where

1) $\mathrm{S}$ is a subject experiencing desire,

2) $X$ is an object of desire,

3) $\triangle \mathrm{PSS}$ is the change of the Pleasantness of the State of the Subject:

$$
\operatorname{DESIRE}_{\mathrm{S}, \mathrm{X}}=\Delta \mathrm{PSS}_{\mathrm{S}, \mathrm{X}}=\mathrm{PSS}_{\text {end }}-\mathrm{PSS}_{\text {beginning }}
$$

The above definition and formula of desire are consistent both with hedonistic/utilitarian approach to desire and with the contemporary point of view, that "...the primary linkage of the notion of desire to a notion other than itself is to the notion of affect - pleasure or displeasure in the widest sense" (Strawson, 2010, p. 284).

A desire is often characterized or measured by its strength. Both positive and negative desire can be experienced as strong or weak. This means that the strength of desire is a sign-independent characteristic of desire. Therefore, a mathematical sign of the magnitude or an absolute value ( $\mid$ value $\mid$ ) should be applied to express strength of the subject's (S) desire for X $\left(\triangle \mathrm{PSS}_{\mathrm{S}, \mathrm{X}}\right)$ : the strength of a subject's $\mathrm{S}$ desire for $\mathrm{X}=\left|\mathrm{DESIRE}_{\mathrm{S}, \mathrm{X}}\right|=\mid\left(\Delta \mathrm{PSS}_{\mathrm{S}, \mathrm{X}} \mid\right.$

\section{Experimental Support of the Proposed Model of Desire}

Changes of pleasantness of the different stimuli (thermal, gustatory, olfactory, auditory, visual) depending on the internal state of a subject were experimentally studied by Cabanac (1971) who gave a special name "alliesthesia" - to the process of such changes:

"In order to avoid using a whole sentence saying that a given external stimulus can be perceived either as pleasant or unpleasant depending upon signals coming from inside the body, it may be useful to use a single word to describe this phenomenon. I hereby propose the word alliesthesia coming from esthesia (meaning sensation) and allios (meaning changed)" (p.1105).

We believe that experiments on alliesthesia contain the experimental support of the proposed model of desire. 
We will demonstrate it by showing a correlation between the sign of the change of pleasantness of the different stimuli described in various experiments (Note 6) and the desirability of these stimuli. In other words, we will see that the change of the stimulus is commonly described as:

1) Desirable or wanted by a subject (S) experiencing it if it is associated with the positive change of pleasantness of this stimulus $(\mathrm{X})$ for a subject $\left(\triangle \mathrm{PSS}_{\mathrm{S}, \mathrm{X}}>0\right)$;

2) Undesirable or unwanted if it is associated with the negative change of $\operatorname{PSS}\left(\Delta \mathrm{PSS}_{\mathrm{S}, \mathrm{X}}<0\right)$;

3) Neither desirable or undesirable (indifferent) if there is no change of pleasantness of a stimulus for a subject $\left(\triangle \mathrm{PSS}_{\mathrm{S}, \mathrm{X}}=0\right)$.

\subsection{Experimental Findings about the Pleasantness of Stimuli}

\section{Insert Figure 1 Here}

Cabanac (2000, p. 1) gave the following description of the Fig. 1: "A hypothermic subject will report pleasure when stimulated with moderate heat, and displeasure with cold. The opposite takes place in a hyperthermic subject". Cabanac (2000) summarized his experimental findings about the hedonics of the thermoregulations as follows:

"We can represent schematically the experimental results of Fig. 1 in Fig. 2. In this double entry table, the thermal states are reduced to three rows: hypothermia, normothermia and hyperthermia. The skin temperature stimuli are also reduced to three columns: cold, tepid, and hot. The table defines nine states where the symbols U, $\mathrm{I}$, and $\mathrm{P}$ indicate whether the stimulus is perceived as unpleasant, indifferent or pleasant. For example, the cell on the top left describes a case of a cold stimulus applied to a hypothermic subject. The sensation in this case is unpleasant which is indicated by a U” (p. 3).

\section{Insert Figure 2 Here}

\subsection{Analysis of the Changes of the Pleasantness of Stimuli}

Let us assess the changes of the stimulus $\mathrm{P}$ looking at the rows of the table of the Figure 2 first from the left to the right and then from the right to the left. We will record the change of $\mathrm{P}(\Delta \mathrm{P})$ in the additional column added to the right side of the original Cabanac's table (3X3 matrix of Figure 2):

\section{Insert Table 2 Here}

The right outmost cell of the first row of the data in the Table 2 describes a change of the pleasantness $(\Delta \mathrm{P})$ of the stimulus for the hypothermic subject experiencing transition from the cold to hot stimulus (because the table is read from the left to the right in this case). The table shows that $\mathrm{P}$ of the stimulus changes from Unpleasant (negative) to Pleasant (positive), therefore the change of pleasantness of the stimulus $\Delta \mathrm{P}$ for a subject is positive,

$$
\Delta \mathrm{P}=\mathrm{P}-\mathrm{U}>0 .
$$

It means that the hypothermic subject experienced positive change of PSS ( $\triangle \mathrm{PSS}>0$ ). This change is represented by the Figure 3, where the "bgn" (beginning) is in the area of $U$ or the negative $P$ and the "end" is in the area of the positive $\mathrm{P}$ :

$$
\text { Insert Figure } 3 \text { Here }
$$

For the second row of the Table $2, \Delta \mathrm{P}=\Delta \mathrm{PSS}=\mathrm{U}-\mathrm{U}=0$, and for the third row it is negative:

$$
\Delta \mathrm{P}=\Delta \mathrm{PSS}=\mathrm{U}-\mathrm{P}<0 .
$$

The opposite changes of the pleasantness happen if we consider the stimulus changing from the right to the left of the Table 3, i.e., in the first row it changes from the hot to cold for the hypothermic subject, etc., as is shown in the Table 3.

\section{Insert Table 3 Here}

\subsection{Analysis of the Changes of the Pleasantness of Stimuli and Its Desirability}

The next step in our analysis of Cabanac's experiments is to answer an additional question about whether the same changes of stimulus are desirable or undesirable for a subject. Let us take another look at Fig. 1. Keeping in mind that all experiments were conducted within the pain threshold, according to Fig. 1:

1) The colder the stimuli the more pleasant it is for the hyperthermic subject;

2) The warmer the stimuli the more unpleasant it is for the hyperthermic subject; 
3) The colder the stimuli the more unpleasant it is for the hypothermic subject;

4) The warmer the stimuli the more pleasant it is for the hypothermic subject.

The essence of the next addition to these observations is that the colder one becomes, the more one wants or desires to get warm, and the hotter one is, the more one wants or desires to cool down. This suggestion is actually close to the application of what Schroeder (2004) called "an interesting lemma of common sense":

"From this fact follows an interesting lemma of common sense: that pleasure and displeasure can provide useful information about one's preferences or desires. "What do you want to eat?" asks Tom. "I don't know," Susan answers. "Let me look into the fridge and see." Looking into the fridge allows Susan to survey the options, and whatever induces pleasant interest will be chosen, Susan's pleasure being a better guide to her current preferences than her intellect" (p. 74)

Thagard (2006) provides a similar observation:

"I once knew someone who told me that she made decisions by first flipping a coin, with heads for one option and tails for another. When the coin came up heads, she would note her emotional reaction, which gave her a better idea of whether she really wanted the option associated with heads" ( $p$ 14).

Schroeder's "lemma of common sense" here calls for the acceptance of well known facts that, generally speaking:

1) A hypothermic subject not only enjoys transition from the cold environment to the hot one but also desires such a change, and

2) A hyperthermic subject not only enjoys transition from the hot environment to the cold one, but also desires it.

Based upon these observations the previous group of four initial statements can be augmented as follows:

1) The colder the stimuli the more pleasant and desirable it is for the hyperthermic subject;

2) The warmer the stimuli the more unpleasant and Undesirable it is for the hyperthermic subject

3) The colder the stimuli the more unpleasant and Undesirable it is for the hypothermic subject ;

4) The warmer the stimuli the more pleasant and desirable it is for the hypothermic subject.

These additions can be schematically represented in Tables 4 and 5 below, which simply extend Tables 2 and 3 (correspondingly) by adding another column for 'desirable/undesirable' on the right. We will again read tables first from the left to the right for the Table 4, then from the right to the left for the Table 4, and record in the right outmost column whether the corresponding changes of the stimulus are desirable or not. For example, the right outmost cell of the first row of the Table 4 describes transition from the cold to hot stimulus as "desirable" for the hypothermic subject (the table is read from the left to the right in this case).

\section{Insert Table 4 Here}

It reflects a well-known fact that a hypothermic subject usually enjoys the transition from the cold environment to the hot one and also desires such a change. Similar considerations are applied in order to complete the rest of the cells in the desirability columns of Tables 4 and 5.

\section{Insert Table 5 Here}

Tables 4 and 5 show that:

1) A stimulus is called 'desirable' (or 'wanted') if it is associated with the positive change of the pleasantness of the state of a subject;

2) A stimulus is not called either 'desirable' or 'wanted' if it is associated with no change of the pleasantness of the state of a subject, i.e., no desire is reported;

3) A stimulus is called 'undesirable or 'unwanted' if it is associated with the negative change of the pleasantness of the state of a subject.

We can represent these findings in the table format in the Table 6.

\section{Insert Table 6 Here}

Table 6 based on Cabanac's experiments shows a correlation between the sign of the $\Delta \mathrm{P}$ change and the desirability/undesirability of the stimulus. Table 6 matches Table 1 that was created based upon the theoretical premises about the definition and formula of desire prior to taking into account Cabanac's experiments. Therefore, we can consider these premises to be now validated by the Cabanac's experiments for the thermal 
stimuli.

\section{Applicability and Advantages of the Discussed Model of Desire}

The same correlation between stimuli and the pleasantness of the internal state of a subject called by Cabanac an "alliesthesia" was confirmed by the Cabanac's experiments for the gustatory and olfactory stimuli (Cabanac 1971) and, recently for auditory and visual stimuli as well (Brondel \& Cabanac, 2007). For example,

"The case of pleasure aroused by eating shows an identical pattern. A given alimentary flavor is described as pleasant during hunger and becomes unpleasant or indifferent during satiety. Measurement of human ingestive behavior confirms the above relationship of behavior with pleasure. It has been repeatedly demonstrated in the case of food intake (Fantino, 1984, 1995), that human subjects tend to consume foods that they report to be pleasant and to avoid those foods that they report to be unpleasant. Pleasure also shows a quantitative influence: the amount of pleasurable food eaten is a function of alimentary restrictions and increases after dieting. The result is that pleasure scales can be used to judge the acceptability of food. Thus, in the cases of temperature and taste, the hedonic dimension of sensation depends directly on the biological usefulness of the stimulus to the subject" (Cabanac, 2000, p. 2).

It suggests that the discussed model of desire should be applicable not only to the thermal sensations, but also to the other ones mentioned above. Moreover, its applicability can be extended further, because this model is consistent with the classical desire definitions presented in the section 2 of this article. For example, according to Aristotle, an angry person experiences on the hedonic level a change from pain of a slight to pleasure of the (prospect of) revenge. This is a positive change from the hedonically negative to the hedonically positive state, i.e., positive $\triangle$ PSS. It converges with our claim, that such a change is usually verbalized as a desire for the phenomenon associated with the more positive state, that is called an object of desire (in the case of anger, the object of desire is revenge).

Mathematical clarity of the Ovsich's model of desire is a step forward from the existing level. Experimental support of the model demonstrated in this paper validates it and also puts on more solid footing models of attention and will (Ovsich, 1998a) based upon this model of desire.

\section{Conclusions}

This article analyzed experiments on changes of pleasantness of the stimuli depending on the internal state of a subject and found a good correlation between their results and a hedonistic model of desire (Ovsich, 1998), defining desire as a term describing changes of the Pleasantness of the State of a Subject (PSS) associated with the desire objects, where DESIRE $\mathrm{S}, \mathrm{X}=\Delta\left(\mathrm{PSS}_{\mathrm{S}, \mathrm{X}}\right)$; STRENGTH of DESIRE $_{\mathrm{S}, \mathrm{X}}=\left|\left(\Delta \mathrm{PSS}_{\mathrm{S}, \mathrm{X}}\right)\right|$.

\section{References}

Aristotle (2004). Rhetoric (T. W. Rhys, Trans.): Dover Publications.

Barrett, L. F. (2006). Valence is a basic building block of emotional life. Journal of Research in Personality, 40, 35-55. http://dx.doi.org/10.1016/j.jrp.2005.08.006

Brondel, L., \& Cabanac, M. (2007). Alliesthesia in visual and auditory sensations from environmental signals. Physiology \& Behavior, 91, 196-201. http://dx.doi.org/10.1016/j.physbeh.2007.02.009

Cabanac, M. (1971). Physiological role of pleasure. Science, 173, 1103-1107. http://dx.doi.org/10.1126/science.173.4002.1103

Cabanac, M. (1981). Physiological signals for thermal comfort. In Cena, K., \& Clark, J. A. (Eds.). Bioengineering, Thermal Physiology, and Comfort (pp. 181-192). Elsevier Scientific Publ., Amsterdam. http://dx.doi.org/10.1016/S0166-1116(08)71089-6

Cabanac, M. (2000). What is Happiness? (Invited lecture). In C. Bonnet (Ed.), Fechner Day 2000, International

Society of Biophysics (pp. 29-34). Strasbourg: Amalgame Impression.

Cabanac, M. (2010). The Fifth Influence. The Dialectics of Pleasure. iUniverse Books, 2010, ISBN: 978-1-4401-8836-7. English translation of the: La cinquième influence, ou La dialectique du plaisir, 2003. Québec: Presses de l'Université Laval.

DeLancey, C. (2002). Passionate Engines: What Emotions Reveal About Mind and Artificial Intelligence. Oxford: Oxford University Press.

Fantino, M. (1984). Role of sensory input in the control of food intake. J. auton. nerv. Syst, 10, $326-347$. http://dx.doi.org/10.1016/0165-1838(84)90032-8 
Fantino, M. (1995). Nutriments et alliesthésie alimentaire. Cah. Nutrit. Diétét, 30, 14-18.

Frankfurt, H. G. (2004). The reasons of love. Princeton, N.J. Princeton University Press.

Katz, L. D. (2005). Three Faces of Desire. Philosophical Reviews, University of Notre Dame. [Online] Available: http://ndpr.nd.edu/review.cfm?id=3861 (2005)

Kenny, A. (1963). Action, Emotion, and Will. London: Routledge and Kegan Paul.

Konstan, D. (2006). The Emotions of the Ancient Greeks: Studies in Aristotle and Classical Literature (Robson Classical Lectures). Toronto: University of Toronto Press.

Locke, J. (1690/1824). An Essay Concerning Human Understanding. Edit 12, Vol. 1. London: Baldwin, Printer 1824.

Marks, J. (1986). The Ways of Desire: New Essays in Philosophical Psychology on the Concept of Wanting. Chicago: Precedent Publishing.

Marks, J. (1986). The Difference between Motivation and Desire. In. J. Marks (Ed.). The Ways of Desire: New Essays in Philosophical Psychology on the Concept of Wanting (pp. 133-147). Chicago: Precedent Publishing.

Mill, J. S. (1861/1961). Utilitarianism. New York: Priest, O. Macmillan.

Ovsich, A. J. (1998a). Outlines of the Theory of Choice: Attitude, Desire, Attention, Will. Proceedings of the 1998 IEEE International Symposium on Intelligent Control (ISIC) Held Jointly with the International Symposium on Computational Intelligence in Robotics and Automation and the Intelligent Systems and Semiotics (ISAS), $\quad p p$ 503-510. [Online] Available: http://ieeexplore.ieee.org/Xplore/login.jsp?url=http\%3A\%2F\%2Fieeexplore.ieee.org\%2Fiel4\%2F5771\%2F1541 5\%2F00713713.pdf\%3Farnumber\%3D713713\&authDecision=-203

Ovsich, A. J. (1998b). Outlines of the Theory of Choice: Attitude, Desire, Attention, Will. Proceedings of the 1998 Twentieth World Congress of Philosophy. [Online] Available: http://www.bu.edu/wcp/Papers/Acti/ActiOvsi.htm

Russell, J. A. (2003). Core affect and the psychological construction of emotion. Psychological Review, 110, 145-172. http://dx.doi.org/10.1037/0033-295X.110.1.145

Schroeder, T. (2004). Three Faces of Desire. Oxford: Oxford University Press. http://dx.doi.org/10.1093/acprof:oso/9780195172379.001.0001

Schueler, G. F. (1995). Desire. Its Role in Practical Reason and the Explanation of Action. Cambridge, Massachussetts: MIT Press.

Spinoza, B. (1674/1955). On the Improvement of the Understanding. The Ethics. Correspondence. New York: Dover Publications, Inc.

Strawson, G. (2010). Mental Reality. The MIT Press.

Tailor C. C. W. (1986). Emotions and Wants. In J. Marks (Ed.) The Ways of Desire: New Essays in Philosophical Psychology on the Concept of Wanting (pp. 217-231). Chicago: Precedent Publishing.

Thagard, P. (2006). Hot Thought. Mechanisms and Applications of the Emotional Cognition. Cambridge, Massachusetts: A Bradford Book, MIT Press.

\section{Notes}

Note 1. Marks, J. (Ed., 1986). The Ways of Desire: New Essays in Philosophical Psychology on the Concept of Wanting. Chicago: Precedent Publishing.

Note 2. Schroeder, T. (2004). Three Faces of Desire. Oxford: Oxford University Press.

Note 3. He also added "the third face of desire" - his own "reward and punishment" theory of desire that was sharply criticized - see, for example, review of Katz (2005).

Note 4. There is a vivid picture of such a hedonic/emotional transition in the Act III of the Verdi's opera "Stifellio".

Note 5. It was called a Pleasantness of the Condition of the Subject in the original 1998 articles.

Pleasantness/valence is a complex variable. A number of sensations, emotions possess their own pleasantness of specific modality. All these $\mathrm{P} / \mathrm{U}$ can be experienced at the same time and are represented by a complex structure, that changes at every given moment. We call it here a Pleasantness of the State of a Subject (PSS). PSS is quite 
close to what is called a Valence of the Core Affect (Russell (2003), Barrett (2006)). For more details see Ovsich (1998a). Please, be advised, that Pleasantness of the State of the Subject (PSS) was called as a Pleasantness of the Condition of the Subject (PCS) in the 1998 articles.

Note 6. See Cabanac 2003, 2010, chapter 3.

Table 1 . The predicted correlation between $\triangle \mathrm{PSS}_{\mathrm{X}}$ and desirability of $\mathrm{X}$

\begin{tabular}{|c|c|c|}
\hline$\Delta \mathbf{P S S}_{\mathbf{S}, \mathbf{x}}$ & Positive $\Delta \mathbf{P S S}_{\mathbf{s}, \mathbf{x}}$ & Desire/Want \\
\hline$\Delta \mathrm{PSS}_{\mathrm{S}, \mathbf{X}}>0$ & Yes & $\begin{array}{c}\text { Yes } \\
\mathrm{X} \text { is desirable } \\
\text { (positive desire) }\end{array}$ \\
\hline$\Delta \mathrm{PSS}_{\mathrm{S}, \quad=0}$ & No & $\begin{array}{c}\text { None } \\
\text { (absence of desire) }\end{array}$ \\
\hline$\Delta \mathrm{PSS}_{\mathrm{S}, \mathbf{X}}<0$ & No & $\begin{array}{c}\text { No } \\
\mathrm{X} \text { is Undesirable } \\
\text { (negative desire) }\end{array}$ \\
\hline
\end{tabular}

Table 2. $\Delta \mathrm{P}$ for the stimulus changing from the left to the right (from cold to hot)

\begin{tabular}{|l|l|l|l|r|}
\hline \multicolumn{5}{|c|}{ Stimulus } \\
\hline Internal State & Cold & Tepid & Hot & $\Delta \mathbf{P}$ \\
\hline Hypothermia & $\mathrm{U}$ & $\mathrm{I}$ & $\mathrm{P}$ & $\Delta \mathrm{P}>0$ \\
\hline Normothermia & $\mathrm{U}$ & $\mathrm{I}$ & $\mathrm{U}$ & $\Delta \mathrm{P}=0$ \\
\hline Hyperthermia & $\mathrm{P}$ & $\mathrm{I}$ & $\mathrm{U}$ & $\Delta \mathrm{P}<0$ \\
\hline
\end{tabular}

Table 3. $\Delta \mathrm{P}$ for the stimulus changing from the right to the left (from hot to cold)

\begin{tabular}{|l|c|c|c|c|}
\hline \multicolumn{5}{|c|}{ Stimulus } \\
\hline \multicolumn{1}{|c|}{ Internal State } & Cold & Tepid & Hot & $\Delta \mathbf{P}$ \\
\hline Hypothermia & $\mathrm{U}$ & $\mathrm{I}$ & $\mathrm{P}$ & $\Delta \mathrm{P}<0$ \\
\hline Normothermia & $\mathrm{U}$ & $\mathrm{I}$ & $\mathrm{U}$ & $\Delta \mathrm{P}=0$ \\
\hline Hyperthermia & $\mathrm{P}$ & $\mathrm{I}$ & $\mathrm{U}$ & $\Delta \mathrm{P}>0$ \\
\hline
\end{tabular}

Table 4. Desirability of the stimulus changing from the left to the right (from cold to hot)

\begin{tabular}{|l|c|c|c|l|c|}
\hline \multicolumn{7}{|c|}{ Stimulus } \\
\hline \multicolumn{1}{|c|}{ Internal State } & Cold & Tepid & Hot & $\Delta \mathbf{P}$ & Desirable/Undesirable \\
\hline Hypothermia & $\mathrm{U}$ & $\mathrm{I}$ & $\mathrm{P}$ & $\Delta \mathrm{P}>0$ & Desirable \\
\hline Normothermia & $\mathrm{U}$ & $\mathrm{I}$ & $\mathrm{U}$ & $\Delta \mathrm{P}=0$ & Neither \\
\hline Hyperthermia & $\mathrm{P}$ & $\mathrm{I}$ & $\mathrm{U}$ & $\Delta \mathrm{P}<0$ & Undesirable \\
\hline
\end{tabular}


Table 5. Desirability of the stimulus changing from the right to the left (from hot to cold)

\begin{tabular}{|l|c|c|c|l|c|}
\hline \multicolumn{7}{|c|}{ Stimulus } \\
\hline \multicolumn{1}{|c|}{ Internal State } & Cold & Tepid & Hot & $\Delta \mathbf{P}$ & Desirable/Undesirable \\
\hline Hypothermia & $\mathrm{U}$ & $\mathrm{I}$ & $\mathrm{P}$ & $\Delta \mathrm{P}<0$ & Undesirable \\
\hline Normothermia & $\mathrm{U}$ & $\mathrm{I}$ & $\mathrm{U}$ & $\Delta \mathrm{P}=0$ & Neither \\
\hline Hyperthermia & $\mathrm{P}$ & $\mathrm{I}$ & $\mathrm{U}$ & $\Delta \mathrm{P}>0$ & Desirable \\
\hline
\end{tabular}

Table 6 . The proven correlation between $\triangle \mathrm{PSSx}$ and desirability of $\mathrm{X}$

\begin{tabular}{|c|c|c|}
\hline$\Delta \mathbf{P S S}_{\mathbf{x}}$ & ${\text { Positive } \Delta \text { PSS }_{\mathbf{X}}}$ & Desire/Want \\
\hline$\Delta \mathrm{PSS}>0$ & Yes & $\begin{array}{c}\text { Yes } \\
\mathrm{X} \text { is desirable } \\
\text { (positive desire) }\end{array}$ \\
\hline$\Delta \mathrm{PSS}=0$ & No & $\begin{array}{c}\text { None } \\
\text { (absence of desire) }\end{array}$ \\
\hline$\Delta \mathrm{PSS}<0$ & No & $\begin{array}{c}\text { No, } \\
\mathrm{X} \text { is Undesirable } \\
\text { (negative desire) }\end{array}$ \\
\hline
\end{tabular}

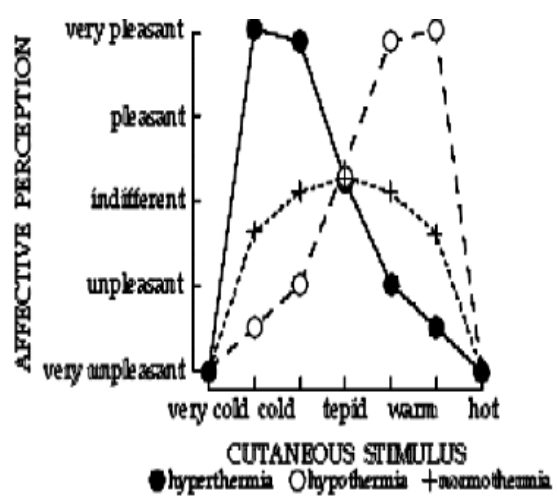

Figure 1. Graphic representation of Cabanac's (2000, p. 2) experimental findings regarding the temperature stimuli pleasure (positive ratings) and displeasure (negative ratings) reported by a subject in response to thermal stimuli presented for 30s on his left hand. During normothermia all stimuli between the threshold for cold and hot pains, are experienced as indifferent. From (Cabanac, 1969; Mower, 1976; Attia, 1984) 


\section{Stimulus}

\begin{tabular}{|l|c|c|c|}
\hline & Cold & Tepid & Hot \\
\hline Hypothermia & $\mathrm{U}$ & $\mathrm{I}$ & $\mathrm{P}$ \\
\hline Normothermia & $\mathrm{U}$ & $\mathrm{I}$ & $\mathrm{U}$ \\
\hline Hyperthermia & $\mathrm{P}$ & $\mathrm{I}$ & $\mathrm{U}$ \\
\hline
\end{tabular}

Figure 2. Simplification of the Figure1 into a $3 \times 3$ matrix

Figure 2. Figure1 is simplified here into a $3 \mathrm{X} 3$ matrix. The hedonic dimension of thermal sensation depends on the subject's internal state. A thermal stimulus feels unpleasant (U), indifferent (I) or pleasant (P) depending on body core temperature. Pleasure is a rare event that occurs only in dynamic situations when a stimulus tends to correct an internal trouble. Indifference is stable. From Cabanac (1981).

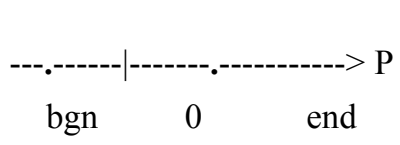

Figure 3. The "beginning" and the "end" of desire formation presented on the hedonic axis 